\title{
Immobilization of Thermolysin by Water-Soluble Reactive Polyurethane: Influence of Charges on the Matrix and Metal-Exchange at the Active-Site
}

\author{
Shigeru KUnUGI, Yoshio MorIKAWA, Mayumi IsHIDA, \\ and Yoshiharu NAKAMURA \\ Department of Applied Chemistry, Fukui University, \\ Bunkyou, Fukui 910, Japan
}

(Received July 9, 1986)

\begin{abstract}
Thermolysin [EC 3.4.24.4] was immobilized by use of a carbamoyl sulfonated urethane prepolymer. The $\mathrm{pH}$ dependence of apparent activity of the immobilized thermolysin was dependent on the species of the introduced diamine; compared with the one obtained with hexamethylenediamine, that prepared with L-lysine showed an optimum $\mathrm{pH}$ shifted to the basic side while an addition of triethylenetetramine shifted the $\mathrm{pH}$ profile to the acidic side. The activity after repeated use was improved by treatment with glutaraldehyde and also by an addition of cobalt(II) ion. The metal ion at the active site of the immobilized enzyme was effectively (though not completely) replaced by a treatment with ethylenediaminetetraacetic acid and the successive addition of metal ion.
\end{abstract}

KEY WORDS Immobilized Enzyme / Thermolysin / Carbamoyl Sulfonated Urethane Prepolymer / Metal Exchange / Polyelectrolyte /

Immobilization of biocatalysts in insoluble matrices has been extensively studied and successfully applied. ${ }^{1-3}$ One of the major classifications of the immobilization procedure is the entrapment of enzyme in gel matrix, which has been highly improved by a development of reactive prepolymer materials by Fukui's school, ${ }^{4}$ in both stability of the immobilized catalyst and versatility of this technique.

Besides the UV-reactive urethane-acryl prepolymers, isocyanate terminated prepolymers derived from poly(ethylene glycol) or poly(propylene glycol) (often cited as urethane prepolymers) have been applied to several catalytic systems. ${ }^{5}$ One problem for these urethane prepolymers, however, is in the high reactivity (or instability) of the free isocyanate group at ambient temperature. Therefore, for example, pre-cooling and quick mixing techniques are necessary for practical applica- tions and a control of the reactivity of the isocyanate group is desired.

In textile finishings, several kinds of isocyanate prepolymers chemically deactivated (blocked) are used. ${ }^{6} \mathrm{By}$, e.g., heat setting they release free isocyanate groups to react with amines or others groups. In most cases, a fairly vigorous heat treatment, well above $100^{\circ} \mathrm{C}$, is required ${ }^{7}$ and therefore they are hard to be applied for biocatalytic systems. When an isocyanate group of urethane prepolymer is blocked by bisulfite to form carbamoyl sulfonate, however, it can be converted to free isocyanate by heating at relatively low temperature in a moderately alkaline solution. $^{8}$ We have studied the usefulness of such carbamoyl sulfonated urethane prepolymers to prepare immobilized enzymes. Here we report the result of an immobilization of thermolysin.

Thermolysin is a thermostable neutral pro- 
tease from $B$. thermoproteoliticus ${ }^{9}$ and widely used for protein structure analysis or peptide syntheses ${ }^{10-12}$ such as aspartame through enzymatic condensation. We have investigated several kinetic aspects of free thermolysin reaction so far, ${ }^{13-15}$ and the results obtained there were useful in the present study. Furthermore the immobilization of this enzyme on various matrices has been performed by other groups ${ }^{16}$ and we can compare the properties of the present system with theirs.

In this study we modified the charges of the immobilization matrices by adding ionizable diamines by analogy with the technique for preparation of ionic urethane resins and investigated the influence of the ionic charges of the matrix on the catalytic behavior of the immobilized enzyme. We also examined the effects of metal exchange in the active-site of immobilized thermolysin.

\section{EXPERIMENTAL}

\section{Materials}

Carbamoyl sulfonated urethane prepolymer was donated as an aqueous dispersion of 20 to $40 \mathrm{w} / \mathrm{w} \%$ by Daiichi Kogyou Seiyaku Co. (Kyoto, Japan). The commercial name is Elastron. The main chain structure of the prepolymer is polyester-polyol and the $M_{r}$ of main chain is around 3000 in total. Thermolysin was donated by Daiwa Kasei Co., Ltd. (Osaka Japan). Other chemicals were of commercial grade and used without further purifications.

\section{Immobilization}

The enzyme mother solution was made with an aqueous solution of ethylene glycol ( $c a$. $20 \%$ final). This medium was necessary since the generally used medium to solubilize thermolysin, ${ }^{17} 2$ to $3 \mathrm{M} \mathrm{NaBr}$ or $\mathrm{KBr}$, caused flocculations by neutralization of the surface charges of the colloidal prepolymers. Conditions for an immobilization were first surveyed by use of bovine serum albumin (Wako, fraction V) and then applied to thermolysin. A typical immobilization condition was as follows: about $4 \mathrm{~g}$ of prepolymer solution were mixed with $1 \mathrm{ml}$ of thermolysin solution (10 mg enzyme $/ 1 \mathrm{ml})$ and with $1 \mathrm{ml}$ of $0.4 \mathrm{M}$ hexamethylenediamine (HMDA) aqueous solution. Then the mixture was spread over a polytetrafluoroethylene plate with a $5 \mathrm{~cm} \times 5 \mathrm{~cm}$ silicone frame and incubated for an hour at $50^{\circ} \mathrm{C}$. The solidified material was washed with cold water for overnight and then stored at $4^{\circ} \mathrm{C}$. In some cases HMDA was replaced by L-lysine or by triethylenetetramine (TETA).

\section{Kinetic Assay}

The activity of the free thermolysin was determined against $N$-furylacryloyl-glycylL-leucineamide $\left(\text { FuaGlyLeuNH }{ }_{2}\right)^{13}$ by observing the absorbance change at $320 \mathrm{~nm}$. The activity of the immobilized system was measured at $37^{\circ} \mathrm{C}$ in $0.1 \mathrm{M}$ Mes or Hepes buffer, unless otherwise mentioned, in vials dipped in a thermostated water bath and shaken gently. Aliquots were taken from the reaction mixture ( $2 \mathrm{ml}$ of reaction solution containing 2 pieces of the resin of $5 \mathrm{~mm} \times 5 \mathrm{~mm} \times 1 \mathrm{~mm}$ ) at intervals and analyzed on a liquid chromatography system (Shimadzu LC6A-Cosmosil $5 \mathrm{C} 18$ ) after quenching the reaction by an addition of twentyfold volume of acetonitrile and filtration (Millipore, FHLP013). The substrate concentration was usually $1 \mathrm{mM}$, well below the $K_{\mathrm{m}}$ value for the free enzyme, ${ }^{13}$ and only the apparent reaction velocity was evaluated.

\section{RESULTS AND DISCUSSION}

Figure 1 shows the $\mathrm{pH}$ dependence of apparent hydrolytic activities of three immobilized thermolysins (a, prepared with an addition of HMDA; b, with L-lysine; c, with TETA). HMDA always gave the most reactive immobilized thermolysins. As reported be- 


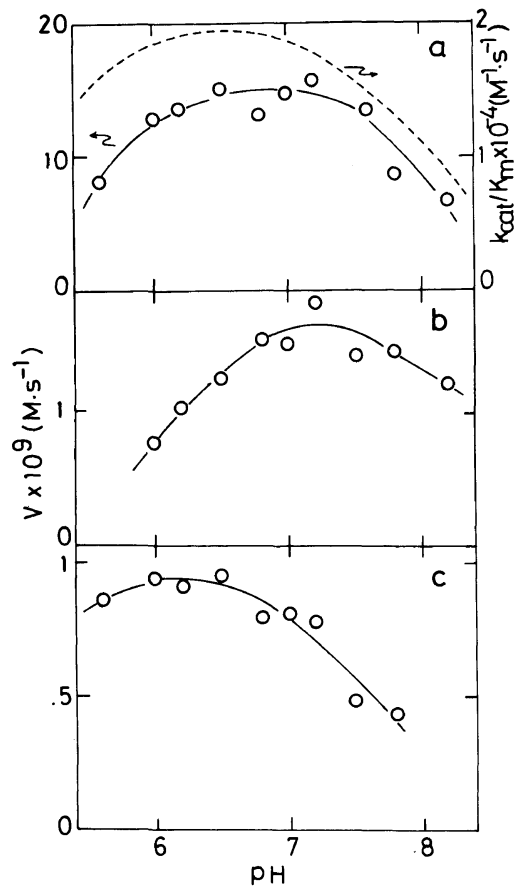

Figure 1. $\mathrm{pH}$-dependences of apparent activity of immobilized thermolysins. (a) An immobilized enzyme prepared with HMDA compared with the reported profile of free thermolysin $(----){ }^{13}$ (b) One with Llysine. (c) One with TETA.

fore $^{13}$ the second-order rate constant of the hydrolysis of this substrate by free thermolysin showed a bell-shaped $\mathrm{pH}$-profile with two $\mathrm{p} K_{\mathrm{a}}$ 's of around 5 and 8.2 (dotted curve). Compared to this, the immobilized thermolysin made by addition of neutral amine (HMDA) gave a $\mathrm{pH}$ profile slightly shifted to the alkaline side (Figure 1a). Immobilized enzymes with ionic amines showed considerable shifts of the optimum $\mathrm{pH}$. When L-lysine was added (Figure 1b), the introduction of a carboxyl group influenced the microscopic $\mathrm{pH}$ in the immobilized enzyme and shifted the optimum $\mathrm{pH}$ towards basic $\mathrm{pH}^{17}$ while the addition of TETA (Figure 1c) shifted the optimum $\mathrm{pH}$ to the acidic side because of the basic nature of one of the two secondary amines introduced.

When we compare the weighed amount of the enzyme in the system, the activity of immobilized enzyme, even at each optimum $\mathrm{pH}$, is less than $1 \%$ of the free one. This low activity may be partly due to leakage of entrapped enzyme during washing. However determination of the entrapped amount of the protein by a usual colorimetric method was unsuccessful because of the presence of an excess amount of the amines in the preparation solution. It is brought about to some extent by thermal inactivation of the enzyme during the heat treatment even for this thermostable enzyme and also by the limited amount of the enzyme readily accessible by the substrate when entrapped within the matrix.

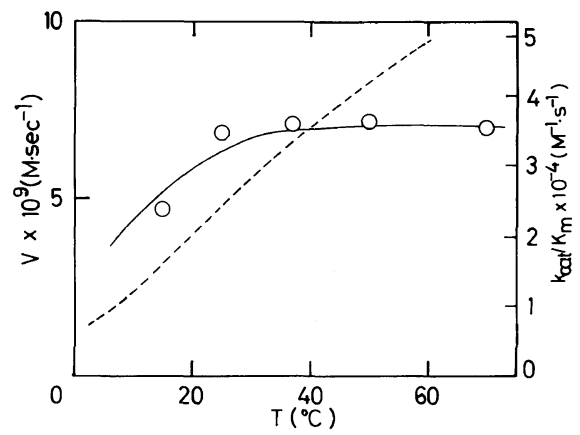

Figure 2. Temperature dependence of the apparent activity of an immobilized thermolysin prepared with HMDA compared with the reported temperature dependence of free thermolysin $(----){ }^{13}$

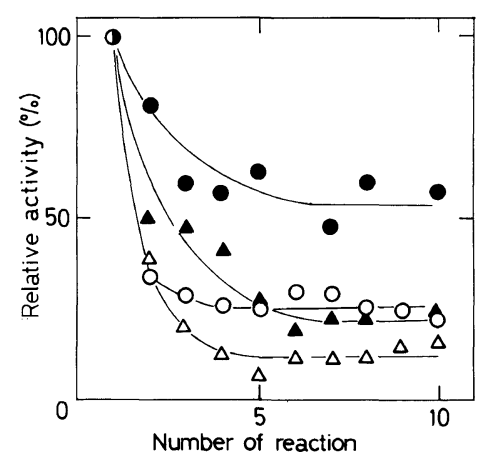

Figure 3. Drop in the apparent activity of an immobilized thermolysin with HMDA after repeated use under various conditions. $(O)$, intact; $(\mathbf{\Delta})$, used in the presence of $1 \mathrm{mM}$ of $\mathrm{CoSO}_{4} ;(\triangle)$ used in the presence of $20 \mu \mathrm{M}$ of $\mathrm{ZnCl}_{2}$; (O) used after treatment with glutaraldehyde $(1 \%, 3 \mathrm{~min})$. 
Figure 2 shows the temperature dependence of the activity of the immobilized enzyme with HMDA compared with the results of free thermolysin reported before. ${ }^{13}$ Above $25^{\circ} \mathrm{C}$, the immobilized thermolysin showed no considerable temperature dependence on activity.

Stored in the cold, the presently prepared immobilized thermolysin maintained its activity for several weeks. The activity after repeated use, however, was not so high (Figure $3, \bigcirc)$; as the second usage the activity decreased about one third of the initial activity but after ten repeated uses it still held more than $20 \%$ of the initial activity. The long term durability was improved by treating the immobilized enzyme with glutaraldehyde $(1 \%, 3 \mathrm{~min}$; Figure 3,0$)$. With this treatment the activity of the immobilized enzyme after ten uses was improved to be around $60 \%$ of the initial. This may be partly due to the crosslinkages between the enzymes and also between the enzyme and the amino group of the matrix.

The activity drop at earlier stage is also improved by supplementing a divalent metal ion such as $\mathrm{Co}^{2+}$ (Figure 3, $\mathbf{\Delta}$ ). When $1 \mathrm{mM}$ $\mathrm{CoSO}_{4}$ was present in the reaction mixture the activities after the second and third uses were

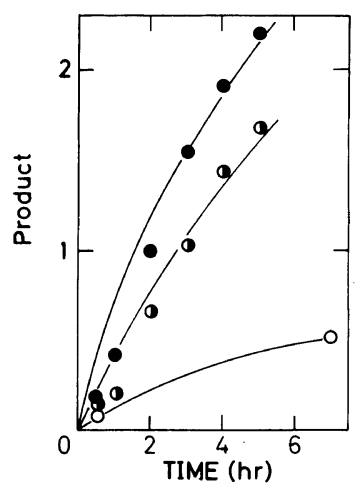

Figure 4. Effects of metal exchange on the apparent reaction curve of the immobilized thermolysin. (O), after treated with EDTA ( $1 \mathrm{mM}, 2 \mathrm{~h}) ;(\bigcirc)$, then $1 \mathrm{mM}$ $\mathrm{CoSO}_{4}$ was added in the reaction mixture; (O), $20 \mu \mathrm{M}$ $\mathrm{ZnCl}_{2}$ was added in the reaction mixture. Ordinate: Area of the product peak read on the integrator for the HPLC signal in arbitrary unit.
50 and $45 \%$ of the initial, respectively. The addition of $\mathrm{Zn}^{2+}$ gave a rather contradictory result $(\triangle)$. Though the original enzyme is a

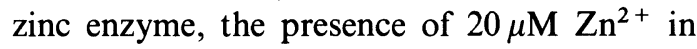
the reaction mixture decreased both the initial activity to about $50 \%$ of the control and the remaining activity after, e.g., five to eight uses, to about $10 \%$ of the initial.

These results are related to the effects of divalent metal ions on the free thermolysin reaction. It was reported ${ }^{18}$ that the presence of $\mathrm{Co}^{2+}$ ion in the system increased the peptide hydrolytic activity of thermolysin while an excess presence of $\mathrm{Zn}^{2+}$ ion rather inhibited the peptidase activity $\left(K_{i \text { (apparent) }}=10-100 \mu \mathrm{m}\right.$ and the maximum activity was observed at $\left.\left[\mathrm{Zn}^{2+}\right]<1 \mu \mathrm{M}\right)$.

When the initially prepared immobilized enzyme was further treated with ethylendiaminetetraacetic acid (EDTA; $1 \mathrm{mM} \mathrm{2h}$ ) to remove $\mathrm{Zn}^{2+}$ ion $(\mathrm{O})$, the apparent activity decreased and was resumed when $\mathrm{Co}^{2+}(\mathbf{O})$ or $\mathrm{Zn}^{2+}(\mathbf{O})$ was added to the reaction mixture (Figure 4). Since the present treatment of EDTA is not sufficient to remove all of the active site $\mathrm{Zn}^{2+}$ ion, a considerable residual activity was observed. The addition of $\mathrm{Co}^{2+}$ gave higher hydrolytic activity than $\mathrm{Zn}^{2+}$ under this particular condition, which is understandable when the reported result on the effect of metal exchange in the free thermolysin reaction is considered as explained above.

Thus we have shown the usefulness of the water soluble urethane prepolymer to immobilize thermolysin effectively, especially to prepare materials having different ionic characters on the matrices. Furthermore the metal ion on the active site of the immobilized enzyme was easily and effectively exchanged, which will be useful for the design of reactivity and specificity of immobilized enzymes.

Acknowledgments. The authors are grateful to Prof. R. Matsuno and Dr. K. Nakanishi, Kyoto University, for their help- 
ful comments.

\section{REFERENCES}

1. "Methods in Enzymology, Immobilized Enzymes," Vol. 44, K. Mosbach Ed., Academic Press, New York, 1976.

2. I. Chibata, "Immobilized Enzymes," Kodansha Ltd., Tokyo, 1978.

3. S. Fukui, I. Chibata, and S. Suzuki, "KousoKougaku," Tokyo Kagakudoujin, Tokyo, 1981.

4. S. Fukui and A. Tanaka, Adv. Biochem. Eng./ Biotech., 29, 1 (1984).

5. S. Fukushima, T. Nagai, K. Fujita, A. Tanaka, and S. Fukui, Biotechnol. Bioeng., 20, 1465 (1978).

6. Z. W. Wicks, Prog. Org. Coat., 3, 73 (1975).

7. G. B. Guise, G. N. Freeland, and G. C. Smith, J. Appl. Polym. Sci., 23, 353 (1979).

8. G. B. Guise, M. B. Jackson, and J. A. Maclaren, Aust. J. Chem., 25, 2583 (1972); G. B. Guise, J. Appl. Polym. Sci., 21, 3427 (1977); G. B. Guise, Adv. Urethane Sci. Technol., 9, 1 (1984).

9. S. Endo, J. Ferment. Technol., 40, 346 (1962); S. A. Latt, B. Holmquist, and B. L. Vallee, Biochem. Biophys. Res. Commun., 37, 333 (1969); H.
Matsubara, "Methods in Enzymology, Proteolytic Enzymes," Vol. 19, G. Perlmann Ed., Academic Press, New York, 1970, p 642.

10. Y. Isowa, M. Ohmori, T. Ichikawa, K. Mori, Y. Nonaka, K. Kihara, K. Oyama, H. Satoh, and S. Nishimura, Tetrahedron Lett., 28, 2611 (1979); K. Oyama, K. Kihara, and Y. Nonaka, J. Chem. Soc., Perkin Trans. 2, 356 (1981).

11. T. Oka and K. Morihara, J. Biochem., 88, 807 (1980).

12. S. I. Wayne and J. S. Fruton, Proc. Natl. Acad. Sci. U.S.A., 80, 3241 (1983).

13. S. Kunugi, H. Hirohara, and N. Ise, Eur. J. Biochem., 124, 157 (1982).

14. M. Fukuda and S. Kunugi, Bull. Chem. Soc. Jpn., 57, 2965 (1984).

15. M. Fukuda and S. Kunugi, Eur. J. Biochem., 142, 565 (1984).

16. K. Oyama, S. Nishimura, Y. Nonaka, K. Kihara, and T. Hashimoto, J. Org. Chem., 46, 5242 (1981); K. Nakanishi, T. Kamikubo, and R. Matsuno, Biotechnology, 3, 459 (1985).

17. Y. Levin, M. Pecht, L. Goldstein, and E. Katchalski, Biochemistry, 3, 1905 (1964); L. Goldstein, Y. Levin, and E. Katchalski, Biochemistry, 3, 1913 (1964).

18. B. Holmquist and B. L. Vallee, J. Biol. Chem., 249, 4601 (1974). 